\title{
Social Media and Clinical Trials Recruitment: Potential Benefits and Challenges
}

\author{
Dean Giustini
}

\section{Introduction}

"...the use of social media in supporting medical research is rapidly moving from experimental pilots to informed strategies. An increasing number of companies and healthcare stakeholders are exploring how social media can support clinical trials... and as they do so, some interesting trends are emerging..." [1].

This column examines the potential uses of social media in the recruitment of patients for clinical trials. Its primary purpose is to provide an overview for health librarians, but clinical trial coordinators and researchers may also find the discussion relevant.

Social networking using internet-based media is fundamentally changing how health researchers think about research and engage patients in clinical trials. Since 2009, social media has been touted as an avenue for clinical trial recruitment [2] and for sharing information with participants [3]. Three of the most popular social media tools, Facebook, LinkedIn, and Twitter, have been used to raise awareness about clinical trials [4-6]. Several dedicated Web sites such as Clinicaltrials.gov and the International Clinical Trials Registry Platform have played crucial roles in helping patients find out about clinical trials [7, 8]. However, social media platforms are now seen to be equally important in communicating research and encouraging patients to participate in clinical studies.

As is true with any new information technology, social media has presented early adopters with a number of possible benefits and challenges. Despite concerns voiced by some in the scientific community, research is steadily moving onto the Web and "into the cloud" (for a definition of cloud computing, see Appendix A). For example, clinical trials rely on human subjects for studies but often have difficulties recruiting enough patients [9]. According to Allison, "one-third of trials fail to recruit a single patient, and fewer than $20 \%$ of clinical trials are completed on time" [2]. Yet, it seems significant that patients using the Web are more likely than the general population to agree to participate in clinical research [2].
Due to the popularity of Facebook and consumer health Web sites such as PatientsLikeMe, the use of social media in clinical research should be closely evaluated. In 2011, at a Cochrane Collaboration workshop, the top six reasons for using social media in clinical research were: $(i)$ to recruit patients for clinical trials, (ii) to encourage interprofessional communication and collaboration, (iii) to develop virtual patient interactions and training, (iv) to set up health advocacy groups, $(v)$ to promote funding and fundraising opportunities, and ( $v i$ ) to issue public health alerts [10]. Given the complexity of information ecosystems on the Web, the question is whether health librarians can play advisory roles for research teams who may be interested in using social media. As the relevant issues are discussed in this paper, keep in mind what parts of the discussion might directly apply to health librarians.

\section{Health 2.0: the patient-centred Web}

The use of social media in patient care is part of what some experts call Health 2.0, or the patient-centred Web. Health 2.0 can be defined as ". . . health care that employs social media and other Web-based tools to promote collaboration between patients, caregivers, medical professionals, and other stakeholders" [11]. Patient narratives cocreated on the Web are at the heart of Health 2.0 and provide mechanisms for two-way interactivity between patients and providers. Unidirectional practices from a former era in health care seem to be relics of a paternalistic time. Now electronic patients, or e-patients as they are commonly called, are "actively engaged members of healthrelated social media networks who rely on social media for their health information" [12]. Online patient communities such as MediGuard and ClinicalResearch (for a list of e-patient communities, see Appendix B) are two excellent examples of social tools that promote the awareness of clinical trials and crowd-sourced information exchanges [2].

In any case, a number of concerns must be discussed before the tools can be used by clinical research coordinators [13]. Lack of ethical and regulatory frameworks for

Dean Giustini. University of British Columbia, Biomedical Branch Library, Vancouver General Hospital, 700 West 10th Avenue, Vancouver, BC V5Z 1L5, Canada.

Corresponding author (e-mail: dean.giustini@ubc.ca). 
social media is a major concern in Canada and the United States. Scientists in government agencies such as the US Food and Drug Administration have been grappling with the potential impact of social media on patient privacy and confidentiality [13]. Some experts say Congress' work on new legislation will require issuing warnings about marketing products to patients via social media [14]. Other debates focus on third-party posts about drugs and medical devices and whether pharmaceutical companies can be held liable for patients' comments about off-label uses.

Prior to this revolution in two-way communication on social media, information was regularly presented to patients unilaterally by health providers [4]. Of course, this still exists in many hospitals and doctors' offices today. But with the social tools and information sources now available to patients, this approach to information dissemination is no longer viable. Health 2.0 patients want to move fluidly from interacting with others and sharing relevant information to locating high quality research at the click of a mouse. A critical component of Health 2.0 is the implied collaboration it introduces for doctors and their patients. After all, patients must learn to speak directly to physicians about their problems. Health 2.0 sites assist patients in learning how to talk to (and debate with) doctors [15] and in finding solutions to their problems in collaboration with others.

Other challenges may arise for patients using social media, and they must be dealt with. First, there is the real danger of information overload. The overwhelming amount of contradictory information online is a problem and a major health literacy challenge for consumers [16]. Not only is misinformation worrisome but patient anger at the system is often openly expressed. This is why some physicians are reluctant to engage with patients in conversations on social media without the usual filters that come with face-to-face communication. The need to speak freely and without filters, however, is why patients use social media. Seizing the enormous potential for patient empowerment, clinical trial recruitment firms want to talk directly to patients and have begun to ask patients directly for their participation in clinical trials [17].

As the world gradually moves online, researchers have taken steps to learn about the norms that apply in online patient communities [18]. Obviously, engaging patients online presents a few obvious dangers. Some drug companies are carefully monitoring patient activities online and are gauging whether or not they will participate in such an open environment [14]. In the United States, the Health Insurance Portability and Accountability Act stipulates, for example, that patient information must be "de-identified" before it is transmitted online [2]. However, how many patients truly understand the public nature of these Web sites? Will patients wrongly identify family members in conversations online? Who will monitor and correct this disclosure? In Canada, the Change Foundation in Toronto believes that the main stumbling block in the adoption of social media is the "lack of best practices that might enable organizations to be less risk-averse" [19]. Similar to their American counterparts, Canadian researchers have expressed their concerns about breaches of patient confidentiality in social media spaces as they currently are configured.

\section{The power of social media}

The power of social media to reach new global audiences is obvious. Facebook, the most popular social media platform in the world, has attracted more than one billion users, or about 1/7 of the global population [20]. According to at least one study, Facebook was shown to be the most efficient platform in recruiting patients for clinical trials [21]. Companies such as Johnson \& Johnson and Pfizer have used YouTube and Facebook, respectively, to reach patients. Social media's reach and on-the-go portability make it very attractive to both researchers and drug companies. The advent of iPads and iPhones makes mass communication via smartphones much easier. However, at least one study suggests that regulators in the European Union are struggling with the global nature of clinical trials and the need to tighten regulations and international standards for the protection of the public and the research process itself [22].

Dozens of pharmaceutical companies are using social media to accelerate their recruitment strategies as most delays in conducting trials stem from recruitment [2]. Clinical trials in oncology also fail to meet their enrollment targets and some never enroll any patients. Some cancerbased LinkedIn groups bring together patients and their doctors and have even been used to find surgeons who will remove inoperable cancers. The Association of Clinical Research Organizations recently announced the launch of its YouTube channel "... to educate the public, media, and policymakers about clinical trials and the growing role of clinical research in drug development" [23]. The power of social media, while undeniable, requires judicious sharing of best practice. Health librarians are advised to share their ideas.

\section{PatientsLikeMe - a 2.0 site with social reach}

According to a 2012 study, "PatientsLikeMe (PLM) and 23 andMe are the leading [web sites] of ... crowdsourced health research" [24]. What is PLM? PLM is a socialnetworking site that brings together "patients like me" from around the world; it has about 150000 registered patients who are organized into 19 disease-specific communities [24, 25]. PLM's business model emphasizes openness and transparency; it is a private company that supports patient recruitment for clinical trials by providing members with a platform for invitations to active clinical trials.

The PLM Web site offers access to several online communities and categorizes patients into five domains: (i) amyotrophic lateral sclerosis, (ii) Parkinson's disease, (iii) HIV/AIDS, (iv) multiple sclerosis, and (v) mood disorders such as depression. PLM is upfront about its funding model and says it sells aggregated information from the use of its site to drug, device, and insurance companies. According to Sarasohn-Kahn, when "groups of people come together to aggregate opinions and data, 
there will be a valuable data stream collected; the value of the data can then be monetized in a variety of ways" [11].

Some of the patient data sources on PLM, such as symptoms and specific drugs as well as demographic information, are closely tracked. Patients share their stories, views on treatment, and the benefits and side effects of drugs and complementary therapies such as herbal medicine, massage, yoga, and so on. The site is indispensable for anyone needing information about rare conditions and for those wanting to speak to others. Patients are able to find other patients like them by searching the site for specific diseases, conditions, age groups, treatments, and symptoms.

\section{Pfizer's clinical trial "in a box"}

Pfizer, which calls itself the world's largest researchbased pharmaceutical company, launched a new program in 2011 called "clinical-trial-in-a-box" [26]. The project was said to be the first randomized trial of its kind, allowing patients to participate completely from home. Regardless of geography or proximity to the researchers, patients were able to participate in a virtual trial through the use of a mobile phone [27]. Pfizer stated publicly on its blog, ThinkScienceNow, that it wants to "transform the role of the patient as a participant in clinical trials", and is committed to improving the experience for patients [28]. Pfizer hopes its approach to research will ultimately save patients' lives and save the industry time and money.

In early 2012, after so much press, Pfizer decided to discontinue its virtual trials project. Craig Lipset, Head of Clinical Innovation at Pfizer, said in a June 2012 blog post: "I also want to clarify that [our withdrawal of the virtual trial] does not represent a failure for or withdrawal from the use of the Internet or social media for patient recruitment. We routinely use the Internet as a channel for recruitment in our studies and will continue to do so wherever it is appropriate. Recruitment strategies tend to be very study specific, and we will be working to refine such strategies specific to a virtual trial approach" [29]. Despite the setback, Pfizer seems to be committed to engaging patients virtually, and to using social media more strategically in future projects.

\section{Suggestions for the future}

What lessons can health librarians learn from the Pfizer experience? First of all, one of the most important lessons is to think strategically before using social media [18]. Matching the features of a social media tool to the specifications of a project is important. Second, learn as much as you can about social media and participate in your local CHLA/ABSC chapter's projects. Before developing Health 2.0 strategies for your organization, think about how you might build trust and credibility with a community of e-patients [12]. Where possible, if you venture into Health 2.0, share your personal experiences and expertise with patients as much as possible. The frequency with which you engage should be timely and consistent. Some Health 2.0 Web sites include active patient navigators who point patients to legitimate $\mathrm{Web}$ sites at the National Library of Medicine such as MedlinePlus and PubMed. Health librarians can provide similar referrals, including which libraries locally a patient might visit to find evidence-based information.

Pharmaceutical companies and researchers are advised to respect the private online spaces of patients. Although some companies are waiting to hear from regulatory agencies about social media, this shouldn't prevent them from creating their own in-house codes of conduct and policies [12]. E-patients are very savvy about commercial intrusion into their online lives and may resent some of the inevitable virtual arm-twisting [12]. According to at least one institutional review board (IRB), the number of negatives on social media surpasses the positives, so unless you want to challenge boundaries, try to remember not to make the following mistakes:

- Don’t promise positive outcomes for any investigational drug or clinical trial.

- Don't communicate that any drug or product is safe or provides superior results.

- Don't say any medical device or product is approved by any regulatory body.

- Never promise free treatment or emphasize incentive payments.

As much as possible, in using Health 2.0 Web sites, try to use the spaces as information channels and help patients to understand their eligibility for and interest in clinical trials. Many IRBs in the United States do not have policies or guidance in place to resolve misunderstandings that occur online, so it may be prudent to hire a social media expert to help with planning. Keep in mind that once you create a social media presence and identity for a clinical trial, maintaining your accounts in good standing requires determination and a long-range plan.

Just like any library or information service, reference questions received over social media require a timely response. Many of the principles that health librarians apply to reference services also apply online to social media. In fact, there is no reason why health librarians can't stake a legitimate claim to being experts in social media; the tools and trends of the digital age are part of the information literacies we monitor, use, and teach. Finally, given the massive increase in the use of social networking tools in health care, more research is needed - and health librarians should participate. The real and anticipated benefits and potential risks of using social media should be evaluated, especially when our users are affected by them during the course of their research and provision of care.

\section{References}

1. Ghinn D. Pharma gets social: pharma lessons in social media and clinical trials. PharmaForum. 21 March 2012. [cited 1 October 2012]. Available from: http://www.pharmaphorum. com/2012/03/21/pharma-gets-social-pharma-lessons-socialmedia-clinical-trials/.

2. Allison M. Can web 2.0 reboot clinical trials? Nature Biotech. 2009;27:895-902. 
3. Coons S. Communication through social media: its potential and pitfalls. Res Prac. 2012;13(2):44-50.

4. Wicks P, Massagli M, Frost J, Brownstein C, Okun S, Vaughan T, et al. Sharing health data for better outcomes on PatientsLikeMe. J Med Internet Res. 2011;12(2):e19 doi:10.2196/jmir.1549.

5. Mantel G. Clinical trials in social media: after the trial, patients go home and $\log$ on. PharmaPhorum. [cited 19 September 2012.] Available from: http://www.pharmaphorum.com/2012/ 09/19/clinical-trials-social-media/.

6. Scanfeld D, Scanfeld V, Larson EL. Dissemination of health information through social networks: Twitter and antibiotics. Am J Infect Control. 2011;38(3):182-8. doi:10.1016/j.ajic. 2009.11.004.

7. Clinicaltrials.gov [Internet]. Bethesda (MD): National Institutes of Health. [Updated 2012 Sep 30; cited 1 October 2012]. Available from: http://clinicaltrials.gov.

8. International Clinical Trials Registry Platform (ICTRP) [Internet]. Geneva: World Health Organization. [cited 1 October 2012]. Available from: http://www.who.int/ictrp/en/.

9. Hawn C. Take two aspirin and tweet me in the morning: how Twitter, Facebook, and other social media are reshaping health care. Health Aff. 2009;28(2):361-8. doi:10.1377/ hlthaff.28.2.361.

10. Giustini D, Grajales F, Hooker D. Using social media to promote evidence-based practice. Cochrane Canada Symposium. 2011 Feb 16. [cited 1 October 2012]. Available from: http://hlwiki.slais.ubc.ca/index.php/Using_Social_Media_to_ Promote_Evidence-Based_Practice.

11. Sarasohn Kahn J. The wisdom of patients: social media in health care. THINK Health for California Healthcare Foundation, 2008.

12. Blue Chip Patient Recruitment. Engaging e-patients in clinical trials through social media: patient recruitment and the e-patient: a survey analysis. [cited 1 October 2012]. Available from: http://bluechipmarketingworldwide.com/BCPR_form/ BlueChip_SocialMedia_5-2011.pdf.

13. Glickman SW, Galhenage S, McNair L. The potential influence of Internet-based social networking on the conduct of clinical research. J Empir Res Hum Res Ethics. 2012; 7(1):71-80. doi:10.1525/jer.2012.7.1.71.

14. Sullivan J, Planell M, Goldman D. The FDA and the regulation of social media. Corporate Counsel. 2012 June 27. [cited 1 October 2012]. Available from: http://www.law.com/ corporatecounsel/PubArticleCC.jsp?id = 1202560843256\&The_ FDA_and_the_Regulation_of_Social_Media.

15. Baron-Epel O, Dushenat M, Friedman N. Evaluation of the consumer model: relationship between patients' expectations, perceptions and satisfaction with care. Int $J$ Qual Health Care. 2001 Aug;13(4):317-23.

16. Daley T. Consumer health information sources in the $21 \mathrm{st}$ century. DJIM. 2011;7.
17. Reynolds T. Clinical trials: can technology solve the problem of low recruitment? BMJ. 2011 Jun 14;342:d3662.

18. Kietzmann JH, Hermkens K. Social media? Get serious! Understanding the functional building blocks of social media. Bus Horiz. 2011;54(3):241-51. doi:10.1016/j.bushor.2011.01.005.

19. Using social media to improve healthcare quality: a guide to current practice and future promise. Toronto: Change Foundation; 2011. [cited 1 October 2012]. Available from: http://www.changefoundation.ca/docs/socialmediatoolkit.pdf.

20. Giustini D, Yu A. Social media in clinical trials: benefits and challenges in a changing e-landscape [Internet]. [2012 $10 \mathrm{Sep}$; cited 2012 September 28]. Available from: http://www.slideshare. net/giustinid/social-media-clinical-trials-recruitment-2012.

21. Baldwin M, Spong A, Doward L. Patient-reported outcomes, patient-reported information: from randomized controlled trials to the social web and beyond. Patient. 2011;4(1):11-7. doi:10.2165/11585530-000000000-00000.

22. Foulkes M. Social contexts, social media, and human subjects research. Am J Bioeth. 2011 May;11(5):35-6.

23. ACRO launches YouTube channel [Internet]. Washington (DC): Association of Clinical Research Organizations. [2012 March 19; cited 1 October 2012]. Available from: http://www. acrohealth.org/acro-launches-youtube-channel.html.

24. Swan M. Crowdsourced health research studies: an important emerging complement to clinical trials in the public health research ecosystem. $J$ Med Internet Res. 2012;14(2):5. doi:10.2196/jmir.1988.

-25. Wicks P, Massagli M, Frost J, Brownstein C, Okun S, Vaughan T, Bradley R, et al. Sharing health data for better outcomes on PatientsLikeMe. J Med Internet Res. 2010 Jun 14;12(2):e19. doi:10.2196/jmir.1549.

26. Goosen R. Is Pfizer's virtual clinical trial model a failure? [Internet]. New Orleans (LA): RebarInteractive. [2012 March 23; cited 1 October 2012]. Available from: http://rebarinter active.com/pfizer-virtual-clinical-trial/.

27. Silverman E. Pfizer ends social media bid for trial recruitment. Pharmalot. 19 June 2012. Available from: http://www. pharmalot.com/2012/06/pfizer-ends-social-media-bid-for-trialrecruitment/.

28. Lipset, Craig. Virtual Clinical Trials to Improve Patient Participation and Access. 2011 June 7 [cited 2012 September 28]. In: ThinkScienceNow Blog [Internet]. New York: Pfizer Inc. Available from: http://www.thinksciencenow.com/blogpost/virtual-clinical-trials-to-improve-patient-participationand-access/.

29. Lipset, Craig. Talk about It. Apply what worked. Fix what didn't. 20 June 2012 [cited 1 October 2012]. In: ThinkScienceNow Blog [Internet]. New York: Pfizer Inc. Available from: http://www.thinksciencenow.com/blog-post/ talk-about-it-apply-what-worked-fix-what-didn $\% \mathrm{E} 2 \% 80 \% 99 \mathrm{t} /$. 


\section{Appendix A}

Cloud computing is a type of computing where software is accessed and stored out on the open Web "in the cloud", literally "out there in cyberspace", instead of locally on desktop computers. Cloud computing usually involves common applications that are accessed from within a Web browser while the software and data are stored remotely.

Crowdsourcing in Health 2.0 refers to a distributed form of outsourcing the creation of knowledge. It can be used to refer to finding large groups of people who share similar interests, such as patients who use social media sites to share and create knowledge.

E-patients are health consumers who use the Internet regularly to gather information about medical conditions and/or illnesses and who uses social media to do so. An e-patient can also be defined as an "actively engaged member of health-related social media networks who relies on social media for health information..."

Health 2.0 is a more participatory, patient-centred model of healthcare. It emphasizes online (public or private) interactivity between consumers, health providers, and librarians on social networks and an ability to share medical information, patient data, and anecdote to improve health outcomes on a global scale.

Online (and virtual) health communities: There are many online, virtual health communities available to e-patients on the Web and via social media platforms such as Facebook, Twitter, and LinkedIn as well as via niche Web sites such as PatientsLikeMe and 23andme.

Social media engagement: The direct interaction with e-patients in online health communities is a form of social engagement. A form of social media engagement with patients is currently being pursued to locate participants for clinical trials.

\section{Appendix B}

\section{Health 2.0 Web sites}

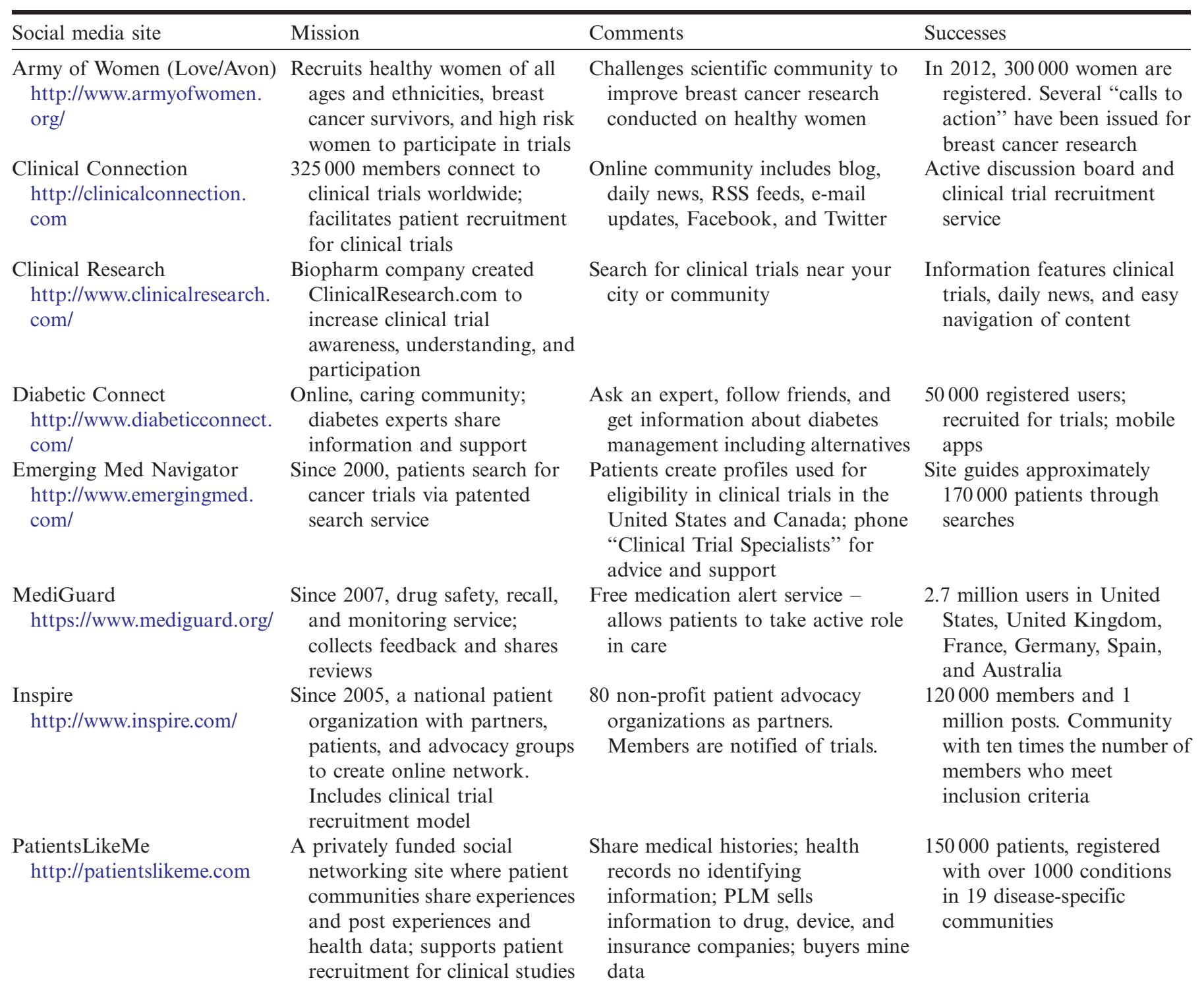


Appendix B (Continued)

\begin{tabular}{|c|c|c|c|}
\hline Social media site & Mission & Comments & Successes \\
\hline $\begin{array}{l}\text { Social Heart Study } \\
\text { https://socialheartstudy.org/ }\end{array}$ & $\begin{array}{l}\text { A new social network based } \\
\text { project and research study that } \\
\text { recruits patients on the } \\
\text { Internet }\end{array}$ & $\begin{array}{l}\text { Aims to discover how social } \\
\text { networks such as Facebook } \\
\text { contribute to cardiovascular } \\
\text { health; ways of preventing } \\
\text { cardiovascular disease }\end{array}$ & $\begin{array}{l}\text { Collaboration between two } \\
\text { California university } \\
\text { medical schools. Recruit } \\
\text { target is one million. }\end{array}$ \\
\hline $\begin{array}{l}\text { Sermo } \\
\text { http://www.sermo.com/ }\end{array}$ & $\begin{array}{l}\text { Since } 2006 \text {, an exclusive } \\
\text { community for physicians who } \\
\text { post observations and } \\
\text { questions arising in their } \\
\text { practice }\end{array}$ & $\begin{array}{l}68 \text { medical specialties discuss } \\
\text { treatment options, network for } \\
\text { expert advice; share opinions once } \\
\text { credentials are verified }\end{array}$ & $\begin{array}{l}\text { More than } 125000 \text { physician } \\
\text { members. Anonymity if you } \\
\text { want it. American Medical } \\
\text { Association endorsed Web } \\
\text { site until } 2009 \text {. }\end{array}$ \\
\hline $\begin{array}{l}\text { TrialX } \\
\text { http://trialx.com/ }\end{array}$ & $\begin{array}{l}\text { Connects patients to clinical } \\
\text { trials and develops innovative } \\
\text { technologies and media to } \\
\text { facilitate patient recruitment }\end{array}$ & $\begin{array}{l}\text { Web-based platform that uses } \\
\text { algorithms and social networks to } \\
\text { help patients find clinical trials } \\
\text { matching health conditions }\end{array}$ & $\begin{array}{l}17000+\text { clinical trials } \\
\text { approved by US Food and } \\
\text { Drug Administration; } \\
100000+\text { trial searches; } \\
15000+\text { volunteers; } 10000 \\
\text { + connections made }\end{array}$ \\
\hline
\end{tabular}

